\title{
APROXIMAÇÕES ENTRE OS CONTEXTOS LOCAL E NACIONAL EM PRÁTICAS DE EDUCAÇÃO AMBIENTAL NA ESCOLA
}

\author{
Alexandre Harlei Ferrari ${ }^{1}$ \\ Maria Cristina de Senzi Zancul ${ }^{2}$
}

Resumo: $O$ presente artigo tem por objetivo discutir alguns conceitos e conteúdos referentes a práticas de Educação Ambiental (EA) na escola, tomando como foco duas pesquisas, uma realizada em âmbito local e outra em nível nacional. A primeira é resultado de um estudo sobre as práticas de EA realizadas em escolas de Ensino Fundamental da rede municipal de ensino de Araraquara/SP e a segunda, intitulada "O que fazem as escolas que dizem que fazem educação ambiental" é uma pesquisa de âmbito nacional, realizada pela Secretaria de Educação Continuada, Alfabetização e Diversidade (SECAD) do Ministério da Educação (MEC). Procuramos identificar pontos comuns que aparecem nos dois estudos, bem como algumas divergências, traçando um paralelo entre as dimensões presentes em uma realidade específica e o contexto mais amplo da EA desenvolvida nas escolas. Buscamos apontar "o que é feito", "como é feito" e "por quem é feito", no contexto da educação ambiental escolar, e concluímos destacando aspectos que consideramos como relevantes neste confronto entre o particular e o geral.

Palavras-chave: Educação Ambiental; Práticas Pedagógicas; Projeto PolíticoPedagógico.

1 Secretaria Municipal de Educação - Araraquara. E-mail: alexandre.ferrari@techs.com.br. 2 Faculdade de Ciências e Letras, UNESP-Araraquara. E-mail: mczancul@fclar.unesp.br 


\section{Introdução: abordagem inicial}

A Educação Ambiental (EA) tem, como uma de suas possibilidades, proporcionar aos alunos experiências concretas de intervenção no meio social, fornecendo subsídios significativos e legítimos para que esses alunos se coloquem como atores do próprio processo de ensino-aprendizagem, visando a formação de uma consciência ecológica ativa, crítica e ética (FERRARI, 2009).

Segundo Lima (2004, p.106), a EA parte do diagnóstico de que a crise ambiental é consequência do esgotamento de um projeto de civilização que "entendeu progresso e conhecimento como dominação e controle", tornando a razão instrumental o caminho mais eficiente para a "conquista do poder econômico e político que coloniza e degrada a vida humana e não humana".

Para o autor, a EA pode ser entendida como um instrumento libertador de mudança social e cultural que, juntamente com outras iniciativas políticas, sociais e econômicas, procura responder aos desafios postos pela crise socioambiental que vivenciamos. Em tal contexto, "a educação ambiental emancipatória compartilha desse inconformismo e da aspiração de 'reinventar o mundo' a partir da desconstrução e da reconstrução do presente" (LIMA, 2004, p.108).

Ao considerar a EA como possibilidade transformadora, Reigota (1998, p.48), assevera que existe um "espaço para momentos onde ocorrem transmissão de conhecimento, construção do conhecimento e a desconstrução das representações sociais", permitindo que o processo pedagógico aconteça sob diferentes aspectos que se complementam uns aos outros.

De acordo com o autor, a inserção da temática ambiental no cotidiano escolar, ao permitir a "interação entre ciência e cotidiano" e "conhecimento científico, popular e representações sociais", possibilita a "participação política e intervenção cidadã" dos sujeitos envolvidos (REIGOTA, 1998, p.48).

Ainda segundo Reigota (2004, p.35), a EA não deve estar "baseada na transmissão de conteúdos específicos, já que não existe um conteúdo único, mas sim vários", especialmente quando se consideram as diferentes faixas etárias a que se destinam e os "contextos educativos em que se processam as atividades". Para ele, o principal é que os conteúdos sejam originados do "levantamento da problemática ambiental vivida cotidianamente pelos alunos e que se queira resolver", sendo que esse levantamento pode e deve ser feito em conjunto por alunos e professores.

Com relação à Educação Ambiental escolar, os Parâmetros Curriculares Nacionais - PCN (BRASIL, 1997), ainda hoje representam um importante documento, que pode contribuir para nortear 0 trabalho dos professores. De acordo com os PCN, o trabalho com Meio Ambiente (MA) tem, como papel principal, colaborar para a "formação de cidadãos conscientes, aptos para decidirem e atuarem na realidade socioambiental", levando os indivíduos a se "comprometerem com a vida, com o bem-estar de cada um e da sociedade, local e global" (BRASIL, 1997, p.25).

revista brasileira

educação ambiental 
Nesse sentido, os PCN apontam que, além de fornecer informações e conceitos, a escola deve se propor a "trabalhar com atitudes, com formação de valores, com o ensino e a aprendizagem de habilidades e procedimentos" (BRASIL, 1997, p.25).

Assim, entendemos que as práticas de EA realizadas nas escolas podem e devem contribuir de forma decisiva para as ações dos indivíduos frente aos problemas ambientais encontrados em seu cotidiano, de forma que possam elaborar propostas com vistas a possíveis encaminhamentos e soluções.

Partindo de tais considerações, buscamos neste artigo, discutir aspectos das práticas de EA realizada nas escolas, tomando dois estudos, o primeiro deles realizado em nível local e o segundo, que contém os resultados obtidos com uma pesquisa em nível nacional. Trazemos, primeiramente, a pesquisa realizada no Mestrado em Educação Escolar intitulada Educação Ambiental em Escolas de Ensino Fundamental da Rede Municipal de Araraquara: do Projeto Político Pedagógico à Sala de Aula (FERRARI, 2009), e, na sequência, a pesquisa que tem como título $O$ que fazem as escolas que dizem que fazem educação ambiental (TRAJBER; MENDONÇA, 2006). Na análise sobre o estudo mais amplo, procuramos apontar alguns pontos comuns que aparecem nas duas pesquisas, bem como algumas divergências, buscando traçar um paralelo entre as dimensões presentes em uma realidade específica e o contexto mais amplo da EA desenvolvida nas escolas.

\section{A pesquisa local}

A pesquisa que retrata uma realidade local foi realizada entre março de 2007 e agosto de 2009, em Araraquara, uma cidade do interior paulista e buscou investigar o que era feito em termos de EA nas escolas da rede municipal de ensino fundamental da cidade (FERRARI, 2009).

Foram selecionadas oito escolas de ensino fundamental, das treze que funcionavam naquele momento, ficando fora da pesquisa três unidades escolares ligadas ao projeto Escolas do Campo (duas situadas em assentamentos agrários e uma em um distrito municipal), e outras duas que foram inauguradas no período em que o estudo estava sendo realizado ${ }^{3}$.

Em nossas análises tomamos como base a documentação oficial (orientações pedagógicas, parâmetros curriculares nacionais, regulamentações e leis no âmbito federal, estadual e municipal), além de autores cuja obra e experiência com a temática ambiental contribuem para o entendimento da questão no contexto da educação escolar formal.

${ }^{3}$ Atualmente a rede municipal de Araraquara/SP é composta por 14 unidades escolares de ensino fundamental do primeiro ano nono ano, atendendo 7.126 alunos matriculados nesta modalidade. Fonte: INEP - Censo Escolar 2012. Disponível em: $<$ http://portal.inep.gov.br/web/guest/basica-censo >. Acesso em: 21 mar. 2016. 
Nossos procedimentos metodológicos incluíram a análise das propostas de EA contidas nos projetos político-pedagógicos das escolas selecionadas e entrevistas, com roteiro semiestruturado, com os Coordenadores Pedagógicos e com os Professores que desenvolviam práticas com a temática ambiental.

Através da Secretaria Municipal de Educação, obtivemos acesso aos Projetos Político-Pedagógicos (PPP) de todas as unidades escolares, bem como às dependências das escolas e entramos em contato com coordenadores pedagógicos e professores que, voluntariamente, aceitaram participar da pesquisa e concederam as entrevistas.

A investigação revelou aspectos significativos sobre o trabalho com a temática ambiental nas escolas, tanto do ponto de vista dos conteúdos tratados quanto dos fundamentos teóricos para as práticas.

Por meio da análise dos PPP, de entrevistas com diversos profissionais nas escolas e com os professores que desenvolviam projetos voltados a Meio Ambiente, procuramos construir um panorama da EA na rede municipal de ensino da cidade de Araraquara (SP).

Dos dados obtidos na pesquisa, destacamos alguns para a presente discussão: 1) os conteúdos dos PPP referentes à temática ambiental e os fundamentos que os embasam; 2) a percepção, por parte dos coordenadores pedagógicos, acerca da temática ambiental nos PPP e o trabalho com Educação Ambiental; 3) os projetos desenvolvidos nas escolas de acordo com as informações fornecidas pelos professores e coordenadores.

\section{Os conteúdos dos PPP referentes à temática ambiental}

A análise realizada a partir das informações dos PPP das escolas pesquisadas levou em conta dois aspectos: 1) os conteúdos da proposta pedagógica orientados para atividades com a temática ambiental, ou seja, aquilo que, de acordo com os documentos, deveria estar sendo feito na escola naquele momento, de modo geral e nas disciplinas, de modo particular (atividades, projetos e ações sobre temas ambientais); 2) os fundamentos ou referências teóricas que alicerçavam as propostas, os conteúdos e atividades sugeridos e programados com a temática ambiental.

A partir da análise do documento, verificamos que embora recheados de conteúdos pedagógicos sobre aprendizagem, cidadania, desenvolvimento de habilidades cognitivas, alfabetização etc., os PPPs apontavam um "panorama multifacetado no que se refere à Educação Ambiental" (FERRARI, 2009, p.147). 
O quadro que obtivemos sobre os conteúdos dos Projetos PolíticoPedagógicos quanto aos temas relativos à EA e MA, nos possibilitou as seguintes constatações e análises ${ }^{4}$ :

$\checkmark \quad$ apenas duas escolas apresentavam, esparsamente, algum referencial teórico sobre a temática ambiental sendo essas também as únicas escolas cujo PPP trazia projetos de EA e MA;

$\checkmark \quad$ em quatro escolas, nos quadros anexos dos PPP, foi possível identificar que a temática ambiental era trabalhada via passeios e visitas pedagógicas a centros de EA, parques ecológicos, museus e zoológicos;

$\checkmark \quad$ em uma escola, o PPP não trazia qualquer anotação sobre o trabalho com a temática ambiental, nem mesmo nos anexos;

$\checkmark \quad$ todas as oito escolas recebiam, naquele momento, projetos prontos de órgãos estatais: Aprendendo com a Natureza, da Secretaria de Agricultura e Abastecimento/SP; e PROCEL - Energia Elétrica, do Ministério das Minas e Energia e Indústria e Comércio que propunham abordagem de temas ambientais por meio de atividades pontuais.

A partir de nossos apontamentos, podemos dizer que os PPP das unidades escolares pesquisadas eram desprovidos de conteúdos sistematizados e "não contemplavam uma visão sobre a temática ambiental" (FERRARI, 2009, p.148). Os conteúdos da área não eram tratados como temas essenciais ao processo educativo nem como temas transversais, conforme indicam os PCNs.

\section{A visão dos Coordenadores Pedagógicos sobre a temática ambiental nos PPP e o trabalho com EA}

Da análise sobre a avaliação dos profissionais incumbidos de trabalhar a execução dos PPP no dia-a-dia das escolas naquele momento em que estavam sendo desenvolvidos (2007 a 2009), destacamos alguns aspectos.

É importante ressaltar que, no momento da pesquisa, o PPP encontrava-se numa espécie de transição, uma vez que as escolas passavam por um processo de reestruturação dos documentos, encerrando a proposta de 2007 e construindo outra para o biênio de 2008-2009.

Pudemos observar, na fala dos profissionais entrevistados, que 0 projeto político-pedagógico encerrado em 2007 não apresentava, em relação à

${ }^{4}$ Adaptado de FERRARI, 2009, p.147-148.

Revbea, São Paulo, V. 11, № 1: 66-84, 2016. 
temática ambiental, uma abordagem adequada, chegando mesmo a ser visto como falho neste aspecto.

Conforme as percepções dos coordenadores, havia a necessidade de que o projeto político-pedagógico para o período seguinte (2008-2009) fosse construído dando mais atenção e importância à temática ambiental, de modo que os erros cometidos no projeto anterior não voltassem a ocorrer.

Levando em conta as informações fornecidas nas entrevistas pelos coordenadores pedagógicos sobre os PPP, consideramos que esses profissionais revelavam:

$\checkmark \quad$ uma preocupação legítima de que os novos PPP contemplassem uma gama maior de assuntos referentes a Meio Ambiente, buscando uma formação ética e ecológica dos alunos, tendo em vista a grave situação planetária;

$\checkmark \quad$ o reconhecimento da Educação Ambiental como temática a ser trabalhada para além de modismos ou assuntos populares no campo da mídia (televisão, revistas etc.), uma vez que se referem aos problemas que afetam a vida dos alunos;

$\checkmark \quad$ expectativas de que a Educação Ambiental estivesse mais presente nas propostas e ações educacionais, dada a importância que o tema tomou atualmente. (FERRARI, 2009, p.150-151);

Em relação ao que os coordenadores entendiam por EA, verificamos que a visão dos entrevistados abrangia um "vasto contingente de percepções", que incluía desde uma visão "individualista do tema - eu, o mundo e minha atuação sobre ele", além de concepções de cunho comportamental que eram "aprender a viver junto, ter consciência das ações, tomar atitudes corretas" e ainda acepções de ordem utilitaristas como uso sustentável, conservação e preservação da natureza (FERRARI, 2009, p.160).

A multiplicidade das respostas apresentadas nas entrevistas nos permitiram "construir uma gigantesca colcha de retalhos" que, em sua totalidade, nos oferecia "toda a diversidade que a temática ambiental carrega por natureza". Por outro lado, embora isso pudesse ser visto como muito positivo, significava, em nossa avaliação, "que não existe um fio condutor, um padrão ou mesmo uma orientação, deixando transparecer a existência da contradição e da fragmentação desse conhecimento" (FERRARI, 2009, p.160).

Sobre a forma mais apropriada de se tratar a EA na escola, os coordenadores pedagógicos apontaram que deveria ser uma proposta de trabalho "interdisciplinar" e "coletivo", com destaque para a execução de projetos temáticos, voltados às questões ambientais (FERRARI, 2009, p.160). 
Sobre os temas a serem trabalhados, os profissionais entrevistados apontaram: água (o mais indicado); consumo, consumismo e a produção de resíduos (lixo); recursos naturais; desmatamento; natureza.

Quanto aos temas mais recorrentes abordados pela mídia, naquele momento, os coordenadores pedagógicos assinalaram aqueles que diziam respeito aos problemas com "água e o ar, o lixo e os resíduos de toda espécie, o aquecimento global e o desmatamento das florestas" e que esses temas eram apresentados "quase sempre como questões pontuais e locais, sem relação com os aspectos mais globais que decorrem da maior parte delas" (FERRARI, 2009, p.161).

\section{Os projetos desenvolvidos nas escolas de acordo com os professores e coordenadores}

Em cada uma das oito escolas selecionadas, a partir das respostas obtidas junto aos profissionais entrevistados, levantamos os projetos que estavam sendo desenvolvidos com conteúdos relacionados a meio ambiente e identificamos quem eram os responsáveis por sua proposição e realização.

$\mathrm{Na}$ análise dos dados, observamos uma disparidade entre o que apontavam os coordenadores pedagógicos e o que os professores responsáveis diziam realizar, o que nos levou a tecer as seguintes considerações ${ }^{5}$ :

$\checkmark \quad$ havia um grande descompasso entre os projetos apontados pelos Coordenadores Pedagógicos e Professores, ou seja, muito do que acontecia na escola ficava dentro das salas de aula (individualização dos projetos), sem que houvesse divulgação do que estava sendo feito;

$\checkmark \quad$ diante desta aparente falta de comunicação e isolamento, ficava muito clara a impossibilidade de que os projetos pudessem acontecer de forma interdisciplinar que, de acordo com os próprios profissionais, seria a melhor forma de trabalhar com a temática na escola;

$\checkmark \quad$ por não serem percebidos no cotidiano escolar, por não constarem nos projetos político-pedagógicos, por não terem publicidade/divulgação, os projetos ficavam restritos às iniciativas individuais, estanques em disciplinas, e a momentos pontuais.

É certo dizer que tanto os projetos apontados pelos Coordenadores Pedagógicos quanto aqueles assinalados pelos Professores traziam, para 0 cotidiano escolar, mesmo que pontualmente, uma variação heterogênea de atividades pedagógicas, tanto teóricas como práticas (FERRARI, 2009, p.167).

${ }^{5}$ Adaptado de Ferrari, 2009, p.164-170.

Revbea, São Paulo, V. 11, № 1: 66-84, 2016. 
De qualquer modo, embora as ações dos profissionais em suas respectivas escolas não estivessem embasadas em referenciais teóricometodológicos de uma EA crítica e emancipatória, como é desejado pelas perspectivas mais atuais, aquilo que é preconizado em leis e decretos ou mesmo recomendado pelos próprios teóricos da EA estava sendo realizado de alguma maneira.

Sobre os principais temas dos projetos desenvolvidos nas escolas pesquisadas com a temática ambiental e 0 ano escolar ao qual eles se destinavam, reproduzimos na Tabela $1^{6}$ abaixo aqueles que foram indicados pelos coordenadores pedagógicos e pelos professores.

Tabela 1: Os principais temas e o público alvo dos projetos e/ou atividades em Educação Ambiental realizados na escola, indicados pelos coordenadores pedagógicos e professores responsáveis.

\begin{tabular}{|c|c|c|c|c|c|c|c|c|c|c|c|}
\hline \multirow{2}{*}{ Temas } & \multicolumn{9}{|c|}{ Público Alvo (ano de ensino) } & \multicolumn{2}{|c|}{$\begin{array}{c}\text { Número de vezes } \\
\text { indicados por: }\end{array}$} \\
\hline & 1 & 2 & 3 & 4 & 5 & 6 & 7 & 8 & 9 & CP & Pr \\
\hline MicrobaciasHidrográficas ${ }^{1}$ & & & & & * & & & & & $* * * * *$ & $* * * * *$ \\
\hline Água, Ar e Solo & & & & & * & * & * & & & * & *** \\
\hline Poluição da Natureza & & & & & & * & * & & & & * \\
\hline Cobertura Vegetal & & & & & & & & * & * & & * \\
\hline Ser Humano (Corpo e Saúde) & & & & & * & & & & & * & ** \\
\hline Alimentação e Cadeia Alimentar & & & & & * & & & & & & ** \\
\hline Qualidade de Vida & & & & & & * & * & * & * & ** & \\
\hline Consumo e Produção de Lixo & & & & & * & * & * & & & ** & $* * * * * *$ \\
\hline Lixo e Reciclagem de Materiais & & & & & * & * & * & & & ** & $\star * \star \star \star *$ \\
\hline Estações do Ano e Ciclos da Natureza & & & & & * & & & & & & * \\
\hline Visitas Monitoradas (Temáticas) & * & * & * & * & * & * & * & * & * & * & \\
\hline Viagens e Passeios (Zoológicos) & * & * & * & * & * & * & * & * & * & * & \\
\hline Horta (Plantio, Cultivo, Colheita etc.) & * & * & * & * & * & * & * & * & * & & ** \\
\hline Energia Elétrica (uso e desperdício) & & & * & * & * & * & * & * & * & * & * \\
\hline Feira de Ciências e do Conhecimento & * & * & * & * & * & * & * & * & * & * & * \\
\hline Estudo do Meio & & * & * & & & & & & & & * \\
\hline
\end{tabular}

Legenda: $\mathrm{CP}=$ Coordenador Pedagógico; $\mathrm{Pr}=$ Professor.

Nota: 1. Conforme as temáticas abordadas no Projeto Aprendendo com a Natureza.

${ }^{6}$ Apresentado originalmente na Dissertação de Mestrado como Tabela 15 (FERRARI, 2009, p.171).

Revbea, São Paulo, V. 11, № 1: 66-84, 2016. 
A partir da análise dos dados sobre os principais temas abordados, destacamos:

$\checkmark \quad$ a heterogeneidade destes temas, com ênfase nos grupos "água, ar e solo", "consumo e produção de lixo"; e "lixo e reciclagem de materiais" que, notadamente, são os temas mais próximos do aluno e costumam ser abordados de forma pontual no trabalho pedagógico em EA desenvolvido nas escolas de modo geral;

$\checkmark \quad$ o fato de que, para muitas escolas, a temática ambiental era amplamente realizada por alunos em todos os anos de ensino, através de visitas monitoradas, viagens e passeios, além de atividades em horta e participação em feiras de conhecimento.

Se, por um lado, água/consumo/lixo/reciclagem são os temas que aparecem mais vezes indicados nos trabalhados de EA, por outro lado os passeios/visitas/feiras são os mais apontados em termos de abrangência, por envolverem toda a escola, enquanto que os temas específicos direcionavam-se a públicos específicos.

No que se refere aos principais objetivos relacionados ao desenvolvimento dos projetos em EA identificados nas escolas, segundo os profissionais entrevistados, o conjunto de informações levantadas está organizado na Tabela $2^{8}$ - página seguinte (FERRARI, 2009, p.172).

Observamos nas informações obtidas, que os objetivos apontados para se trabalhar a Educação Ambiental nas escolas voltavam-se ao campo individual, apontando que o aluno deve produzir "uma mudança de hábito em si" como "necessidade crucial para a qualidade de vida dele e da sustentabilidade do planeta" (FERRARI, 2009, p.173-174).

7 O tema "Microbacias Hidrográficas" aparecia significativamente indicado por um mesmo número de coordenadores e professores por ser um tema comum aos $5^{\circ}$ s anos em função do projeto "Aprendendo com a Natureza".

8 Apresentado originalmente na Dissertação de Mestrado como Tabela 16 (FERRARI, 2009, p.173). 
Tabela 2: Os principais objetivos dos projetos e/ou atividades em Educação Ambiental nas escolas pesquisadas, de acordo com os coordenadores pedagógicos e professores entrevistados.

\begin{tabular}{|c|c|c|}
\hline Escola & Profissional & Principais Objetivos: \\
\hline \multirow[b]{2}{*}{ Escola.1 } & Coordenador & $\begin{array}{l}\text { - Cumprir o programa da Secretaria Municipal da Educação (SME) - } \\
\text { (referia-se ao projeto Aprendendo com a Natureza). }\end{array}$ \\
\hline & Professor & $\begin{array}{l}\text { - Fazer com que o aluno se sinta parte do meio onde ele vive e interaja da } \\
\text { melhor maneira possível, desempenhando no Planeta Terra um papel } \\
\text { que, de alguma forma, não venha a prejudicar o planeta, não pensando } \\
\text { só em se beneficiar. }\end{array}$ \\
\hline \multirow[b]{2}{*}{ Escola.2 } & Coordenador & $\begin{array}{l}\text { - Conhecer a biodiversidade, trabalhando para a preservação da mata } \\
\text { ciliar - (referia-se ao projeto Aprendendo com a Natureza). }\end{array}$ \\
\hline & Professor & $\begin{array}{l}\text { - A formação do cidadão, pois a EA chama a atenção para isso; } \\
\text { - } \quad \text { A produção oral e escrita da Língua Portuguesa (matéria que ministra); } \\
\text { - Formar o cidadão atuante no espaço da sociedade. }\end{array}$ \\
\hline \multirow[b]{2}{*}{ Escola.3 } & Coordenador & $\begin{array}{l}\text { - A complementação dos conteúdos pedagógicos estabelecidos nos } \\
\text { planejamentos. }\end{array}$ \\
\hline & Professor & $\begin{array}{l}\text { - Formar o cidadão consciente, de modo a pensar no aluno quando ele } \\
\text { sair da escola, enquanto cidadão do mundo. }\end{array}$ \\
\hline \multirow{2}{*}{ Escola.4 } & Coordenador & - Ligados aos temas propostos, conforme os projetos desenvolvidos. \\
\hline & Professor & - Conscientizar o aluno e a comunidade para a mudança de hábitos. \\
\hline \multirow[b]{2}{*}{ Escola.5 } & Coordenador & - A mudança do comportamento do aluno. \\
\hline & Professor & $\begin{array}{l}\text { Educar para eles [os alunos] terem atitudes corretas e positivas em } \\
\text { relação ao lugar onde vivem, modificando sua postura pessoal em } \\
\text { relação ao meio ambiente. }\end{array}$ \\
\hline \multirow[b]{2}{*}{ Escola. 6} & Coordenador & $\begin{array}{l}\text { - A conscientização das crianças, futuros adultos, que vão governar e } \\
\text { herdar o planeta; } \\
\text { - Conhecer, aprender e assimilar de forma significativa os conteúdos. }\end{array}$ \\
\hline & Professor & $\begin{array}{l}\text { - Mostrar a realidade para os alunos, destacando o que nós podemos } \\
\text { fazer a partir da sala de aula, levando para casa, formando pessoas } \\
\text { críticas. - (porém salienta que não tem visto resultado, não vê mudanças } \\
\text { nas atitudes dos alunos). }\end{array}$ \\
\hline \multirow[b]{2}{*}{ Escola.7 } & Coordenador & $\begin{array}{l}\text { - A conscientização para a mudança de hábitos, tentando mostrar o perigo } \\
\text { dos atuais comportamentos. }\end{array}$ \\
\hline & Professor & $\begin{array}{l}\text { - Como não há projetos específicos na escola, fica mais evidente a } \\
\text { questão de sobrepor o individualismo, substituindo-o por uma cultura } \\
\text { coletiva. }\end{array}$ \\
\hline \multirow{2}{*}{ Escola.8 } & Coordenador & - (sem representante). \\
\hline & Professor & $\begin{array}{l}\text { - Fazer com que eles [os alunos] adquiram uma consciência ambiental, } \\
\text { para a qualidade de vida deles mesmos. }\end{array}$ \\
\hline
\end{tabular}

No mais, assinalamos, em nossas considerações, o seguinte:

$\checkmark$ fica a impressão de que se encontra centrada no aluno a responsabilidade pelas mudanças futuras, a fim de garantir uma espécie de "desenvolvimento sustentável" da humanidade, a partir da conscientização e tomada de atitudes positivas por parte deles (hoje crianças, amanhã adultos); 
$\checkmark \quad$ observa-se que a Escola é vista como foco central desse processo de mudança de atitudes, hábitos e comportamentos, não havendo qualquer menção a outras instâncias da sociedade como co-responsáveis pelas mudanças esperadas;

$\checkmark \quad$ os objetivos apresentados fogem ao escopo de um trabalho pedagógico realizado enquanto tomada de ação política, embasada em preceitos e fundamentos teórico-conceituais ou mesmo filosóficos em Educação Ambiental;

$\checkmark \quad$ inexiste uma proposta político-pedagógica nas unidades escolares pesquisadas que, alicerçadas em fundamentos teóricos, deem conta de construir objetivos claros sobre o trabalho em Educação Ambiental ou com a temática ambiental (FERRARI, 2009, p.174).

Diante do exposto, podemos dizer que nossa pesquisa proporcionou um levantamento sobre o trabalho com a temática ambiental nas escolas, permitindo-nos apontar, com alguma propriedade, o que estavam fazendo as escolas que diziam fazer Educação Ambiental na rede municipal de ensino de Araraquara/SP.

\section{A pesquisa nacional}

A pesquisa intitulada $O$ que fazem as escolas que dizem que fazem educação ambiental, publicada pela SECAD/MEC ${ }^{9}$ em 2006, foi organizada por Rachel Trajber e Patrícia Ramos Mendonça e traz, por sua vez, um panorama sobre as práticas de EA nas escolas de todo o Brasil, buscando fornecer subsídios para a discussão da temática em questão.

Segundo as organizadoras do trabalho, coube à SECAD, órgão ministerial de fomento às políticas públicas e de apoio aos sistemas de ensino, por meio da Coordenação-Geral de Educação Ambiental, conduzir a pesquisa, que tornou possível organizar uma avaliação das práticas em EA nas escolas do país (TRAJBER; MENDONÇA, 2006).

De acordo com seus autores, a pesquisa "O que fazem as escolas...", realizada em duas etapas, a primeira delas a partir das respostas do censo escolar no período de 2001 a $2004^{10}$, possibilitou identificar a "universalização

${ }^{9}$ Publicada pela Secretaria de Educação Continuada, Alfabetização e Diversidade (SECAD) do Ministério da Educação (MEC) em parceria com a representação no Brasil da Organização das Nações Unidas para a Educação, Ciência e Cultura (UNESCO), no ano de 2006.

${ }^{10}$ Cabe dizer que para esta etapa da pesquisa foi contratado, pela CGEA/SECAD/MEC, o Instituto de Estudos do Trabalho e Sociedade (IETS), com o objetivo de realizar as análises dos dados relativos à EA contidos nos censos escolares. O IETS é uma organização privada, sem fins lucrativos e, segundo informações em seu sítio institucional, é "voltada para a produção e a disseminação de conhecimento na área social”. Disponível em: <http://www.iets.org.br/>. Acesso em 11 jan. 2013.

Revbea, São Paulo, V. 11, No 1: 66-84, 2016. 
da Educação Ambiental praticada nas escolas", cujos resultados dos cruzamentos de dados, permitiu a construção de um índice sintético com a "dimensão da Educação Ambiental como modalidade nas escolas, o tratamento de resíduos sólidos e a participação de eventos na e com a comunidade" (TRAJBER; MENDONÇA, 2006, p.13).

A segunda etapa, iniciada em 2005, teve o objetivo de "aprofundar a compreensão sobre a presença da EA nas escolas públicas, por meio de uma pesquisa direta em algumas delas", resultante de um convite feito a cinco universidades federais ${ }^{11}$, distribuídas por regiões e segundo as experiências de cada uma com a temática ambiental, cujos "coordenadores e/ou responsáveis já participaram de algumas atividades referentes às políticas públicas nesta área" (TRAJBER ; MENDONÇA, 2006, p.14).

Segundo o texto, coube às universidades federais, uma de cada região do país, realizar a pesquisa em dois estados de sua região, selecionando ao todo 420 escolas, conforme os critérios e a organização metodológica definidos em conjunto pela CGEA/SECAD, IETS e Coordenação das universidades federais. Os critérios de escolha dos municípios, a organização dos questionários semiestruturados e do roteiro de observações ficaram definidos nas reuniões da Coordenação-Geral de Educação Ambiental e a fase de pesquisa de campo foi iniciada em maio de 2006.

Com base na descrição das coordenadoras, alguns dos tópicos da análise quantitativa da pesquisa permitiram avaliar as informações sobre como a EA é desenvolvida na escola, quem são os principais sujeitos participantes na sua implementação e quais os objetivos do trabalho com a temática ambiental na escola (TRAJBER; MENDONÇA, 2006, p.16).

Os dados a seguir se referem à análise nacional do estudo $O$ que fazem as escolas que dizem que fazem educação ambiental e fazem parte do capítulo intitulado Análise Nacional: Conteúdos, gestão e percepção da educação ambiental nas escolas, escrito por Carlos Frederico Loureiro, Coordenador da pesquisa na Região Sudeste (UFRJ) ${ }^{12}$, e pelos integrantes da equipe do Instituto de Estudos do Trabalho e Sociedade (IETS), Érica Pereira Amorim, Luísa Azevedo e Maurício Blanco Cossío (LOUREIRO et al., 2006, p.33-77).

Da pesquisa nacional, ora em discussão, procuramos destacar os dados e análises do capítulo acima referido, que nos permitam traçar um paralelo com nosso trabalho desenvolvido localmente.

\footnotetext{
11 Universidade Federal do Rio de Janeiro (UFRJ), Mato Groso do Sul (UFMS), Pará (UFPA), Rio Grande do Norte (UFRN) e Fundação Rio Grande (FURG/RS).

12 Cabe ressaltar, conforme apontado no texto (TRAJBER; MENDONÇA, 2006, p.15 e p.170), que não havia sido aventada, num primeiro momento, a pesquisa no Estado de São Paulo, porém, isto mudou em função da participação, através de um convênio especial com a Unesp de Bauru, sob coordenação da Prof ${ }^{a}$. Marília Freitas de Campos Tozoni Reis.
}

revista brasileira educação ambiental 
Primeiramente os autores ressaltam, a partir dos dados coletados, que a EA, no âmbito das escolas brasileiras, é desenvolvida/realizada por meio de três principais processos ${ }^{13}$ : projetos; disciplinas especiais; e inserção da temática ambiental nas disciplinas, frisando que a distribuição do tratamento da Educação Ambiental nestes três processos não é homogênea (LOUREIRO et al., 2006, p.34).

Os pesquisadores ressaltam a relevância do papel da escola na sociedade e a importância da inserção da EA neste espaço. Para eles,

uma das funções mais importantes da escola é seu poder de transformação e influência da comunidade na qual está inserida. Por outro lado, é na temática ambiental que a escola poderia apresentar um impacto significativo na sociedade, por meio da criação de canais de comunicação com a população, onde seja possível a discussão e reflexão sobre o papel dos cidadãos nas condições socioambientais (LOUREIRO et al., 2006, p.35).

Como primeiro dado da pesquisa nacional, os autores analisam os motivos que dão origem ao trabalho com a temática ambiental nas escolas, identificando que eles estão relacionados, majoritariamente, à ação de um professor ou grupo de professores, ficando em segundo plano, os "parâmetros em ação" e os "problemas ambientais na comunidade". Estes três itens juntos, segundo os autores, representam mais da metade das "motivações" (LOUREIRO et al., 2006, p.43).

Ao compararmos essas constatações aos dados de nosso estudo no mestrado, especialmente quanto ao que tange à "iniciativa de um professor ou grupo de professores", identificamos uma grande semelhança, pois, conforme apontamos, mesmo realizada amplamente nas escolas, EA acontece, muitas vezes, por iniciativa de alguns sujeitos.

Em relação a este aspecto, os pesquisadores apontam para o "importante papel dos educadores como motivadores iniciais dos trabalhos em Educação Ambiental", ao passo que, em contrapartida, o "vínculo institucional entre as escolas e as secretarias estaduais e municiais" é incipiente (LOUREIRO et al., 2006, p.44). Esse é outro ponto que se aproxima dos resultados de nossa pesquisa de mestrado, pois nas análises assinalamos a ausência de um projeto de EA norteado pelas secretarias de educação para as escolas que compõem a rede de ensino de Araraquara.

Um segundo conjunto de informações que destacamos do estudo nacional refere-se aos principais objetivos do trabalho em EA nas escolas. De

13 Estes dados foram obtidos na pesquisa quantitativa realizada pelo IETS no período de 2001 2004, representando a primeira etapa da pesquisa nacional.

Revbea, São Paulo, V. 11, № 1: 66-84, 2016. 
acordo com os autores, o principal objetivo desse trabalho é a conscientização dos alunos e da comunidade para o exercício pleno da cidadania e, em seguida, a sensibilização dos estudantes para o convívio com a natureza, sendo esses dois objetivos representados em mais de $50 \%$ das respostas obtidas na pesquisa (LOUREIRO et al., 2006, p.45).

Para os autores,

se verifica a necessidade de alterar o quadro sobre as percepções do que se coloca como objetivos da Educação Ambiental, incluindo elementos para além da prática discursiva da sensibilização ou conscientização. Limitar os fins da Educação Ambiental à sensibilização do convívio com a natureza e à conscientização para a cidadania plena permite identificar um conceito estreito dessa Educação (LOUREIRO et al., 2006, p.45, grifos nossos).

Essas considerações são similares às que formulamos a partir de nossa investigação junto às escolas da rede municipal de ensino de Araraquara e nos leva a questionar as limitações existentes com relação à EA nas escolas.

A propósito dos dois pontos da pesquisa nacional aqui apresentados motivação e objetivos -, conforme apontado pelos pesquisadores, apenas $38 \%$ (157 escolas das 418 que foram pesquisadas), identificavam trabalhar com EA inserindo a temática no Projeto Político-Pedagógico (LOUREIRO et al., 2006, p.46).

Sobre a forma como a EA é realizada, os pesquisadores pontuam que ela acontece, primordialmente, por meio de projetos, de disciplinas especiais e pela inserção da temática ambiental nas disciplinas comuns, sendo que a grande maioria das escolas acaba por concentrar o trabalho com a temática ambiental em projetos (LOUREIRO et al., 2006, p.46).

No entanto, esses projetos são quase sempre realizados a partir de uma única disciplina do currículo "e, em segundo lugar, a partir da integração de duas ou mais disciplinas" (LOUREIRO et al., 2006, p.47), o que confirma que a temática ambiental acaba sendo desenvolvida na escola de forma não transversal e nem interdisciplinarmente.

A partir dos dados apresentados pelos autores (LOUREIRO et al., 2006, p.47-56), observamos, na pesquisa nacional, que a inserção da temática ambiental em disciplinas específicas vem em segundo lugar nas respostas obtidas; por outro lado, a inclusão como uma disciplina especial é a menos referendada pelas escolas pesquisadas e, ao apontarmos para esses fatos, nos permitimos tecer algumas considerações particulares:

$\checkmark \quad$ que disciplinas específicas tendem a ser aquelas que comumente, por sua característica, estão mais próximas da temática ambiental tratada como algo ligado à natureza - Ciências, Biologia e Geografia -, 
perpassando de forma mais distante as disciplinas de História, Português e outras, como identificamos em nossa pesquisa de mestrado;

$\checkmark \quad$ que disciplinas especiais, mesmo a despeito da recorrente polêmica entre tornar a EA uma disciplina curricular ${ }^{14}$ ou trabalhá-la como tema transversal e interdisciplinarmente, demanda a mobilização de uma série de quesitos (profissionais, espaços, currículo, orientações etc.), e que a maioria das escolas não tem recursos e/ou autonomia para fazêlo.

Quanto aos principais temas abordados no desenvolvimento das atividades em EA, os pesquisadores apontam que a "água" é o que mais aparece nas respostas (indicado por 103 escolas), seguido pelos temas "lixo e reciclagem" (66 escolas), e "poluição e saneamento básico" (30 escolas) (LOUREIRO et al., 2006, p.51).

Nossa pesquisa também indicou a predominância desses mesmos conteúdos: "água, ar e solo"; "consumo e produção de lixo"; e "lixo e reciclagem de materiais", nos trabalhos em EA desenvolvidos nas escolas municipais de Araraquara, destoando apenas o fato de não ter surgido a temática "saneamento básico".

Em relação à inserção da Educação Ambiental nas disciplinas escolares, o estudo revela que, em todas as regiões brasileiras, ela acontece majoritariamente em Ciências Naturais e, em segundo lugar, em Geografia. (LOUREIRO et al., 2006). Na Tabela 3 da página seguinte, reproduzimos os dados do estudo nacional sobre a inserção da EA em disciplinas específicas.

${ }^{14}$ Ver acerca desta discussão: BERNARDES, Maria Beatriz Junqueira; e PRIETO, Élisson Cesar. Educação Ambiental: Disciplina versus Tema Transversal. Rev. eletrônica Mestr. Educ. Ambient. ISSN 1517-1256, v. 24, janeiro a julho de 2010, p.173-185. Disponível em: <http://www.remea.furg.br/edicoes/vol24/art11v24.pdf>. Acesso em: 11 jan. 2013; e TORRES DE OLIVEIRA, Haydée. Educação Ambiental - ser ou não ser uma disciplina: essa é a principal questão?!. In: MELLO, Soraia Silva de; TRAJBER, Rachel (Coord.). Vamos cuidar do Brasil: conceitos e práticas em educação ambiental na escola. Brasília: MEC/CGEA - MMA/DEA / UNESCO, 2007, p. 103-112. Disponível em: <http://portal.mec.gov.br/dmdocuments/publica cao3.pdf>. Acesso em: 11 jan. 2013.

Revbea, São Paulo, V. 11, № 1: 66-84, 2016. 
Tabela 3: Brasil

Inserção da Educação Ambiental em Disciplinas Específicas - 2006

\begin{tabular}{lcccccc}
\hline \multirow{2}{*}{ Disciplinas } & \multicolumn{7}{c}{ Número de escolas } \\
\cline { 2 - 7 } & Centro-Oeste & Nordeste & Norte & Sudeste & Sul & Brasil \\
\hline Matemática & 3 & 3 & 2 & 15 & 11 & 31 \\
\hline Geografia & 7 & 17 & 8 & 50 & 21 & 103 \\
\hline Português & 7 & 8 & 4 & 33 & 18 & 70 \\
\hline Ciências Naturais & 12 & 18 & 10 & 53 & 23 & 116 \\
\hline Língua Estrangeira & 1 & 1 & 2 & 14 & 6 & 24 \\
\hline Educação artística & 7 & 9 & 6 & 28 & 17 & 67 \\
\hline História & 5 & 6 & 6 & 32 & 14 & 63 \\
\hline Educação Física & 4 & 2 & 2 & 17 & 6 & 31 \\
\hline
\end{tabular}

Fonte: Projeto "O que fazem as escolas que dizem que fazem Educação Ambiental". 2006.

Nota: É importante mencionar que o número total de escolas não soma a amostra de 418 escolas pois, uma escola poderia marcar mais de uma disciplina.

Tabela 3: Brasil. Inserção da Educação Ambiental em Disciplinas Específicas - 2006. Fonte: Loureiro et al. (2006, p.53).

Outro ponto significativo destacado pelos autores na pesquisa nacional diz respeito às "percepções das escolas entrevistadas, em relação ao processo de mudanças decorrente da inserção da temática da Educação Ambiental" em seu cotidiano (LOUREIRO et al., 2006, p.65).

Para Loureiro et al. (2006, p.66), a partir das respostas fornecidas pelas escolas, as mudanças que são mais frequentemente percebidas, dizem respeito à: "redução do lixo na escola", "sensibilização dos alunos com a conservação do patrimônio físico", e "melhoria no ambiente físico da escola". Contudo, para os autores,

existe uma dificuldade maior na percepção de modificações nas relações interpessoais como, por exemplo, a solidariedade nas ações cotidianas, a melhoria nas relações dos alunos com o corpo docente e entre os mesmos alunos, e o melhor diálogo entre professores (LOUREIRO et al., 2006, p.66).

Todavia, para os autores, tendo em vista o "papel da escola e a sua relação com o contexto social no qual está inserida", o que mais preocupa é o baixo número de respostas para as questões: "maior participação em campanhas", "maior participação na comunidade" e "maior participação em conselhos e comitês comunitários" (LOUREIRO et al., 2006, p.66).

Concluindo esse tópico de análise, os autores (LOUREIRO et al., 2006, p.70), salientam que a pesquisa mostrou um "sucesso significativo na aproximação da tentativa de conhecer o conteúdo específico que se realiza na 
Educação Ambiental", porém, "apesar de as escolas terem declarado que água, lixo e reciclagem e poluição e saneamento básico são os temas mais abordados", há ainda pautas importantes a serem trabalhadas dentro dos objetivos desta temática, sendo que, para eles,

Esses conteúdos diferem dos objetivos mais frequentemente citados: sensibilização para o convívio com a natureza e conscientizar para a cidadania. No mínimo, a junção destas dimensões impõe a necessidade de aprofundar o estudo dos processos de mediação entre objetivos e conteúdos da Educação Ambiental (LOUREIRO et al., 2006, p.70).

Na sequência do texto, os autores apresentam uma "análise qualitativa no âmbito nacional" (LOUREIRO et al., 2006, p.70-77), na qual realçam aspectos qualitativos dos dados e informações levantados na pesquisa.

Um ponto a destacar refere-se aos laços que as escolas estabelecem com suas secretarias municipais e estaduais, bem como as relações institucionais com o Ministério da Educação (MEC) e suas secretarias educacionais. Conforme os autores,

No geral, a Educação Ambiental está pouco fortalecida na estrutura organizacional de secretarias e as relações entre estas e o MEC são por demais pautadas em fatores conjunturais, dificultando a construção de uma política pública de longo prazo (LOUREIRO et al., 2006, p.72).

A propósito dessa afirmação de que a EA está "pouco fortalecida", tecemos a consideração de que a temática ambiental realizada nas escolas encontra-se afastada daquilo que é proposto em termos organizacionais (oficiais e, portanto, governamentais), havendo um distanciamento e uma significativa falta de articulação entre quem faz (escola) e quem propõe (secretarias, órgãos governamentais) o trabalho em EA.

Por fim, na análise dos resultados da pesquisa de âmbito nacional, sobre o que de fato se faz no trabalho com a temática ambiental, os autores apontam que

as formas de apropriação, significação e realização da Educação Ambiental são múltiplas e não está evidenciado para o universo escolar o que se pretende com a mesma, pelo menos no que se refere ao atendimento das diretrizes da Política Nacional (LOUREIRO et al., 2006, p.72). 


\section{Conclusão: aproximações entre o particular e o geral}

Em nosso trabalho de mestrado apontamos que a EA realizada nas escolas estudadas não conduzia o aluno "ao questionamento e ao aprofundamento das questões ambientais inerentes à sua realidade ou mesmo à realidade global, mas, ao contrário, está arraigada em ideologias dominantes e aspectos naturais" (FERRARI, 2009, p.169).

Dito de outra maneira, o que vimos da EA nas escolas pesquisadas consistia na ausência de um processo de formação e educação política, na falta de um investimento contínuo e permanente na emancipação política dos indivíduos inseridos no cotidiano escolar (FERRARI, 2009).

De fato, quando fomos às escolas, constatamos que o trabalho desenvolvido com a temática ambiental era muitas vezes, "apenas mera coincidência entre atividades do cotidiano escolar e do planejamento pedagógico em Educação Ambiental" (FERRARI, 2009, p.169).

Ao confrontarmos alguns resultados de nossa pesquisa local com o estudo realizado em nível nacional sobre e o que é feito pelas escolas como Educação Ambiental tivemos a pretensão de expor os conteúdos e temas tratados pelas escolas e pelos professores. A partir do que expusemos neste artigo, consideramos que as práticas da Educação Ambiental na escola podem ser relacionadas a três dimensões:

$\checkmark \quad$ a dimensão das prescrições político-administrativas $\rightarrow$ referente aos conteúdos propostos, que se originam fora da escola, elaborados e fundamentados a partir das proposições discutidas em fóruns, conferências, encontros nacionais e internacionais, que concebemos como sendo proposições oficiais;

$\checkmark \quad$ a dimensão dos materiais (conteúdos didáticos e paradidáticos) $\rightarrow$ referente à transposição para os professores daquilo que é proposto na dimensão das prescrições oficiais ou não oficiais, e que se concretizam naquilo que se constitui como os conteúdos que orientam o trabalho da escola e de seus atores;

$\checkmark \quad$ a dimensão da prática $\rightarrow$ a EA realizada pela escola e pelo professor, a fim de atingir os objetivos, metas e proposições contidas nas propostas institucionais/oficiais e curriculares.

Ao traçar um paralelo entre as duas pesquisas, considerando evidentemente as dimensões, competências e metodologias de cada uma delas, não pretendemos justificar a primeira com base nos elementos apresentados na segunda. Nossa intenção é somente buscar validar o que produzimos, aproximando os contextos local e nacional.

Com esta análise dos dados das duas pesquisas, tivemos a intenção de discutir alguns conceitos e conteúdos referentes a práticas de Educação 
Ambiental nas escolas, apontando "o que é feito", "como é feito" e "por quem feito", ressaltando o que aparece como mais relevante nestas práticas.

\section{Referências}

BRASIL. Secretaria de Educação Fundamental. Parâmetros Curriculares Nacionais: meio ambiente e saúde. Brasília: Secretaria de Educação Fundamental, 1997.

FERRARI, A.H.. Educação ambiental em escolas de ensino fundamental da rede municipal de Araraquara: do projeto político-pedagógico à sala de aula. Dissertação (Mestrado em Educação Escolar) - Universidade Estadual Paulista, Faculdade de Ciências e Letras, Campus de Araraquara, 2009.

LIMA, G.F.C. Educação, emancipação e sustentabilidade: em defesa de uma pedagogia libertadora para a Educação Ambiental. In: LAYRARGUES, P.P. (Coord.). Identidades da Educação Ambiental brasileira. Brasília: Ministério do Meio Ambiente - Diretoria de Educação Ambiental, Edições MMA, 2004, p.85-111.

LOUREIRO, C.F.B. et al. Análise Nacional: Conteúdos, gestão e percepção da educação ambiental nas escolas. In: TRAJBER, R.; MENDONÇA, P.R. (Orgs.). Educação na diversidade: o que fazem as escolas que dizem que fazem educação ambiental. Brasília: Secretaria de Educação Continuada, Alfabetização e Diversidade - MEC/UNESCO, edição de 2006, p.33-77.

REIGOTA, M. O que é Educação Ambiental. São Paulo: Brasiliense, 2004.

REIGOTA, M. Desafios à Educação Ambiental escolar. In: CASCINO, F.; JACOBI, P.; OLIVEIRA, J.F. (Orgs.). Educação, meio ambiente e cidadania: reflexões e experiências. São Paulo: Secretaria de Estado do Meio Ambiente: SMA/CEAM, 1998, p.43-50.

TRAJBER, R.; MENDONÇA, P.R.(Orgs.). Educação na diversidade: o que fazem as escolas que dizem que fazem educação ambiental. Brasília: Secretaria de Educação Continuada, Alfabetização e Diversidade MEC/UNESCO, edição de 2006. 